American J. of Engineering and Applied Sciences 4 (4): 477-484, 2011

ISSN 1941-7020

(C) 2014 C. Lim et al., This open access article is distributed under a Creative Commons Attribution

(CC-BY) 3.0 license

\title{
Low Cycle Fatigue Behavior of a Reduced End Plate Moment Connection (T-Stub)
}

\author{
${ }^{1}$ Chemin Lim, ${ }^{2}$ Wonchang Choi, \\ ${ }^{3}$ Emmett A. Sumner and ${ }^{2}$ Taher Abu-Lebdeh \\ ${ }^{1}$ T-Rex Engineering and Construction LC., Houston, Texas 77079, USA \\ ${ }^{2}$ Deparment of Civil, Architectural and Environmental Engineering, \\ North Carolina AT State University, Greensboro, NC 27411, USA \\ ${ }^{3}$ Deperment of Civil Engineering, \\ North Carolina State University, Raleigh, NC 27695 USA
}

\begin{abstract}
Problem statement: In this research, four reduced End Plate Moment Connection (EPMC) specimens (T-stubs) are tested to verify the numerical and theoretical methods for preanalysis of the Low Cycle Fatigue (LCF) behavior of a four-bolt extended unstiffened EPMC. Approach: The T-stub specimens are bolted to a support frame and a monotonic load is applied to the stem plate. Yield line theory and the Kennedy method are used to analyze the strength of the end plates and bolts. The Finite Element Model (FEM) and experimental tests are used to verify the theoretical calculations. Results: The theoretical calculations, FEM results and experimental test results show reasonable relationships. Conclusion: The theoretical calculations could be used to predict LCF behavior of specimens.
\end{abstract}

Key words: Low Cycle Fatigue (LCF), End Plate Moment Connection (EPMC), bolt connection, Finite Element Models (FEMs), The Steel Network (TSN), larger research program

\section{INTRODUCTION}

The study presented in this study is part of a larger ongoing research program to investigate the Low Cycle Fatigue (LCF) behavior of a four-bolt extended unstiffened end Plate Moment Connection (EPMC). The research program is divided into three primary tasks: (i) validate the analytical tools to predict the structural responses of a reduced EPMC (T-stub); (ii) investigate the LCF behavior of the EPMC through experimental tests and analytical modeling and (iii) evaluate the accumulation of LCF damage so that the structure life can be predicted. The focus of this study is to present the details and results of the first task of the larger research program.

The structural steel moment resisting frame system is one of the most popular and efficient structural systems for buildings. If the beam-to-column connections are engineered to induce ductile behavior, the system can provide resistance to lateral movement. However, during the Northridge, California earthquake of 1994, almost 150 structural steel buildings were seriously damaged and several exhibited brittle failure (FEMA, 2000). After an extensive investigation of the unanticipated brittle failure, the SAC Steel Project Joint Venture (created specifically as a result of this Los Angeles area earthquake and funded by FEMA) concluded that the discontinuity of material, stress concentration and LCF were the main reasons for such failure. To address the observed failures, several alternative connection methods for use in welded steel frame structures were investigated as part of the SAC Steel Project.

The EPMC is one of these selected alternative connections. Much of the previous work on EPMCs focused on analysis of the failure of the entire connection, but not on specific individual factors that determine the connection's performance. Therefore, the T-stub model, which had been used widely as a reduced EPMC since 1975, was reintroduced as a possible mechanism to help understand this brittle failure (Murray, 1988). Because most LCF fracture occurs in the end plate (Bursi et al., 2000; Garlock et al., 2003; Mazzolani and Tremblay, 2000), the T-stub is a reasonable reduced EPMC for the focus of LCF analysis. Figure 1 illustrates the specimen adopted for this research. The bolted T-stub connections can fail due to plate plasticity in bending and shear, bolt or weld fracture and/or excessive plasticity of the stem plate in bending. Another potential failure mode is the LCF of the stem or flange plate when subjected to cyclic loading.

Corresponding Author: Wonchang Choi, Department of Civil, Architectural and Environmental Engineering, North Carolina AT State University, Greensboro, NC 27411, USA Tel: (336) 334-7737 Fax: (336) 334-7126 
Am. J. Engg. \& Applied Sci., 4 (4): 477-484, 2011

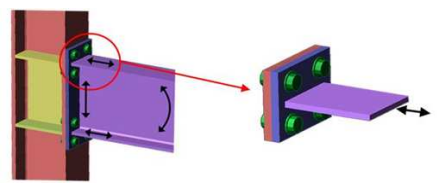

Fig. 1: Reduced end plate moment connection (T-stub)

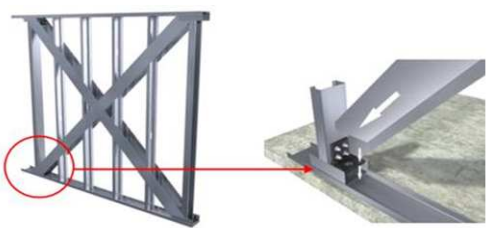

(a)

(b)

Fig. 2: Test components (a) StiffWall® Shear Wall System, (b) Boot and Track Assembly

The objective of the study is to verify the reduced EPMC model through analytical and experimental study. The analytical investigation includes numerical (finite element) and theoretical (yield line) analysis. In the first part of the research, theoretical analysis is conducted to determine the yield level of the structure. In the second part, Finite Element Models (FEMs) are developed to simulate the experimental tests and to verify the theoretical analysis. An experimental investigation is conducted to validate the theoretical analysis and FEM analysis.

In this study, a component of the shear wall system, the T-stub, is tested to define the reduced EPMC behavior characteristics. The tested T-stub specimen is a pre-engineered steel shear wall component for use in the StiffWall® Shear Wall System manufactured by The Steel Network, Inc. (TSN). These shear wall components, shown in Fig. 2, are used in light gauge (cold-formed) steel framing to provide lateral strength and stiffness to the structure. The boot and T-stub in the assembly connects to the vertical framing member, which is a cold-formed stud, while the track connects to the straps that run diagonally across the structure. Then, both the boot and the track are anchored together to the floor, slab, or foundation. Acting together, the boot and track can transfer the lateral forces in a structure to the next component in the load path.

Background: The two main limit states that control the design of the end plate are end plate flexural yielding and bolt tension rupture. Extensive studies have been conducted on the analysis and design of EPMCs using these limits states. The early studies, however, neglect the prying action in the end plate design procedure.
After introduced the so-called 'split tee' analogy to determine the bolt forces (which include the prying action), numerous design procedures emerged that adopted and further developed Kennedy's method. One of these studies (Srouji et al., 1983) uses a unification design procedure that employs yield line theory for end plate yielding and the Kennedy method for bolt failure.

Hendrick et al. (1984); Morrison et al. (1986); Murray (1988); Borgsmiller (1995); Meng (1996) and Sumner and Murray (2000) further developed this design procedure for a variety of EPMC configurations and loading types. These results were used to develop the American Institute of Steel Construction (AISC) design guides (AISC, 2002).

Yield line theory: Yield line theory was first introduced to analyze reinforced concrete slabs. A yield line is a continuous formation of plastic hinges along a straight or curved line. For a specified yield line pattern and loading, a certain plastic moment is required along the hinge lines. To determine the required plastic moment capacity or the failure load, an arbitrary succession of possible yield line mechanisms is selected. The failure mechanism of the slab is assumed to occur when the yield line forms a kinematically valid collapse mechanism. Because elastic deformations are negligible compared to plastic deformations, it has been proven acceptable to assume that the yield lines divide the slab into rigid plane regions. Most of the development of this theory is related to reinforced concrete; however, the principles and findings are also applicable to steel plates. Analysis of a yield line mechanism can be performed two ways. One is the equilibrium method and the other is virtual work (energy method).

The internal energy stored by a yield line mechanism is expressed in the Eq. 1 as:

$\mathrm{W}_{\mathrm{i}}=\sum_{\mathrm{n}=1}^{\mathrm{N}}\left(\mathrm{m}_{\mathrm{px}} \theta_{\mathrm{nx}} \mathrm{L}_{\mathrm{x}}+\mathrm{m}_{\mathrm{py}} \theta_{\mathrm{ny}} \mathrm{L}_{\mathrm{y}}\right)$

where, $\mathrm{m}_{\mathrm{p}}$ is the moment capacity per unit length of the yield line, $E_{n}$ is the relative rotation of the plate on either side of the yield line and $\mathrm{L}$ is the length of the yield line.

The external work that is due to unit displacement at the top of the beam flange is expressed in the Eq 2. as:

$\mathrm{W}_{\mathrm{e}}=\mathrm{F} \times$ Disp.(unit) 


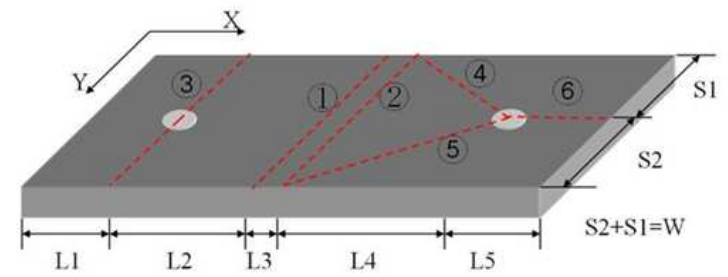

Fig. 3: Yield-line pattern of T-s

Therefore, the equilibrium Eq. 3 is:

$\mathrm{F} \times \operatorname{Disp}=\sum_{\mathrm{n}=1}^{\mathrm{N}}\left(\mathrm{m}_{\mathrm{px}} \theta_{\mathrm{nx}} \ell_{\mathrm{n}}+\mathrm{m}_{\mathrm{py}} \theta_{\mathrm{ny}} \ell_{\mathrm{n}}\right)$

One of the important assumptions in yield line theory is the yield line pattern. Figure 3 shows the chosen yield line pattern of the T-stub. This yield line pattern was developed based upon the observed behavior of the T-stub in the experimental investigation.

The final Eq. 4 for the internal and external work equilibriums of the T-stub is:

$\mathrm{F}=\mathrm{m}_{\mathrm{p}} \times\left(\frac{2 \mathrm{~W}}{\mathrm{~L}_{2}}+\frac{2 \mathrm{~W}}{\mathrm{~L}_{4}}+\frac{4 \mathrm{~L}_{4}}{\mathrm{~W}}+\frac{4 \mathrm{~L}_{5}}{\mathrm{~W}}\right)$

where, $m_{p}=Z \sigma_{y}=\frac{t_{p}{ }^{2}}{4} \sigma_{y}$ and $t_{p}$ is the thickness of the plate and $\sigma y$ is the yield strength of the plate. The calculated force, $\mathrm{F}$, which corresponds to the formation of the yield line mechanism, is calculated using the geometries of the current research specimen shown in Eq. 4.

\section{MATERIALS AND METHODS}

Basic yield line analysis procedures define the flexural responses of the end plate, but they do not predict the bolt forces within the connection. Therefore, the method suggested by Jenkins and Stainsby (1981) is used estimate the bolt forces due to the applied force and the effects of the prying action. The basic assumption in the Kennedy method is that the end plate goes through three different stages of behavior Fig. 4. Q is the prying force, $\mathrm{B}$ is the bolt resisting force and $\mathrm{F}$ is loading. During the first stage, the plastic hinges have not developed and the plate is referred to as 'thick'.

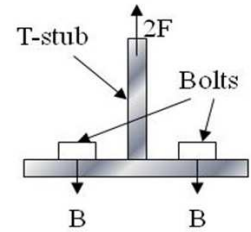

(a)

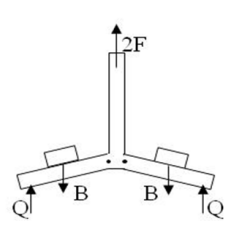

(b)

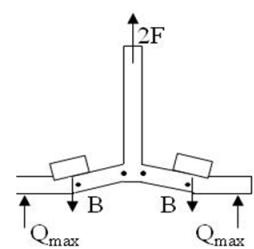

(c)
Fig. 4: Three stages of plate behavior (a) Thick ( $\mathrm{B}=$ F) (b) Intermediate $(\mathrm{B}=\mathrm{F}+\mathrm{Q})$ (c) Thin $(\mathrm{B}=$ F+Qmax)

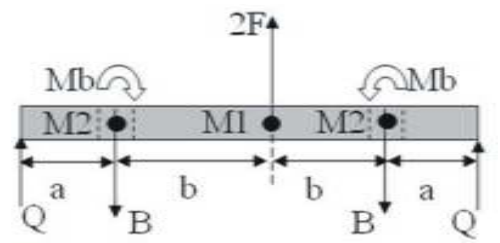

Fig. 5: Static state of the prying effect on the plate

The prying force is taken as zero at this stage. When the plastic hinge forms at the beam flange, the plate becomes intermediate and the prying force is somewhere between zero and the maximum prying force that can occur. The last stage begins when a second plastic hinge forms at the bolt line. The end plate in that stage is considered 'thin and the prying force is at its maximum.

As an example of the plate exhibiting thin plate behavior, Fig. 5 represents the static of the system. M1 and M2 are the moments at the plastic hinge position. Therefore, the equations for the moment of equilibrium for the system are in the Eq. 5-7 as follows:

$\mathrm{M}_{1}=\mathrm{B} \times \mathrm{b}-\mathrm{Q}(\mathrm{a}+\mathrm{b})-\mathrm{M}_{\mathrm{b}}$

$\mathrm{M}_{2}=\mathrm{Q} \times \mathrm{a}$

$\mathrm{F}_{\mathrm{b}} \times \mathrm{b}-\mathrm{M}_{\mathrm{b}}=\mathrm{M}_{1}+\mathrm{M}_{2}$

The general Eq. 8 for the thin plate behavior plate is:

$$
\begin{aligned}
& \mathrm{F}_{\mathrm{b}} \times \mathrm{b}-\mathrm{M}_{\mathrm{b}}=\frac{\mathrm{wt}_{\mathrm{p}}{ }^{2}}{4} \sqrt{\sigma_{\mathrm{y}}{ }^{2}-3\left(\frac{\mathrm{F}}{\mathrm{wt}_{\mathrm{p}}}\right)^{2}} \\
& +\frac{\mathrm{w}^{\prime} \mathrm{t}_{\mathrm{p}}{ }^{2}}{4} \sqrt{\sigma_{\mathrm{y}}{ }^{2}-3\left(\frac{\mathrm{F}}{\mathrm{w}^{\prime} \mathrm{t}_{\mathrm{p}}}\right)^{2}}
\end{aligned}
$$

where, $w$ is the plate width, $w^{\prime}$ is the net plate width, $t_{p}$ is the plate thickness, $\mathrm{F}$ is the plate yielding force and $\sigma_{\mathrm{y}}$ is the strength of the plate. 
Am. J. Engg. \& Applied Sci., 4 (4): 477-484, 2011
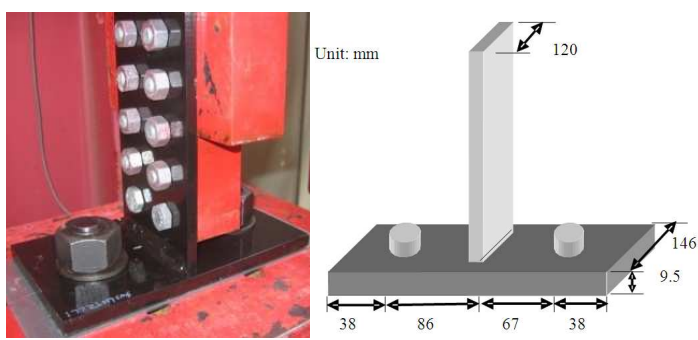

Fig. 6: T-stub specimen

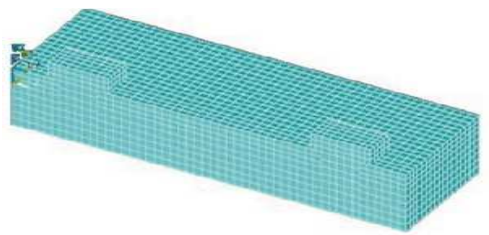

Fig. 7: Half section 3-D FEM model

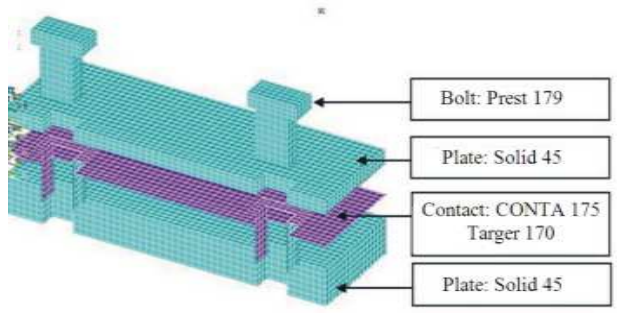

Fig. 8: Element type of FEM model

Therefore, the maximum prying force Eq. 9 is:

$$
\mathrm{Q}_{\max }=\frac{\mathrm{M}_{\mathrm{p}}}{\mathrm{a}}=\frac{\mathrm{w}^{\prime} \mathrm{t}_{\mathrm{p}}{ }^{2}}{4 \mathrm{a}} \sqrt{\sigma_{\mathrm{y}}{ }^{2}-3\left(\frac{\mathrm{F}}{\mathrm{w}^{\prime} \mathrm{t}_{\mathrm{p}}}\right)^{2}}
$$

Specimen strength predictions: Based on the presented theories, i.e., the yield line theory and Kennedy method, the strength of the T-stub specimen can be calculated. Figure 6 shows the specimen and its dimensions.

The plate yield limit is calculated using Equations (3) and (4). The plate material is ASTM A572 Grade50 steel and the yield strength of the material $\left(\sigma_{\mathrm{y}}\right)$ is $50 \mathrm{ksi}$ (345 MPa). Table 1 presents the dimensions of the plate shown in Fig. 3. Therefore, the plate yield force $(F)$ is 19.48 kips $(86.7 \mathrm{kN})$.

The bolt resisting strength $\left(\mathrm{F}_{\mathrm{b}}\right)$ is calculated using Eq. 4. The bolt resisting strength is determined by subtracting the maximum prying force $\left(\mathrm{Q}_{\max }\right)$ from the tensile strength of the bolts (B). The bolts used are ASTM A490 high strength structural bolts with a bolt stud diameter of $7 / 8$ inch $(22.2 \mathrm{~mm})$.
Table 1: The plate dimension

\begin{tabular}{lrrrrrrrrr}
\hline & $\mathrm{L} 1$ & $\mathrm{~L} 2$ & $\mathrm{~L} 3$ & \multicolumn{1}{c}{$\mathrm{L} 4$} & $\mathrm{~L} 5$ & \multicolumn{1}{c}{$\mathrm{S} 1$} & \multicolumn{1}{c}{$\mathrm{S} 2$} & \multicolumn{1}{l}{$\mathrm{W}$} & \multicolumn{1}{c}{$\mathrm{t}_{\mathrm{p}}$} \\
\hline Length, & 1.5 & 3 & 0.75 & 2.625 & 1.5 & 2.875 & 2.875 & 5.75 & 0.375 \\
in, (mm) & -38.0 & -76 & -19.00 & -67.000 & -38.0 & -73.000 & -73.000 & -146.00 & -9.500
\end{tabular}

The tensile strength of the bolt (B) is 68 kips per bolt (302.6 kN per bolt) based on the bolt's material property. The maximum prying force $(\mathrm{Q})$ by using the Eq. (9) is 8.45 kips $(37.6 \mathrm{kN})$. Therefore, the bolt resisting strength $\left(\mathrm{F}_{\mathrm{b}}\right)$ is 59.5 kips per bolt $(264.8 \mathrm{kN}$ per bolt). Each specimen has two bolts, so the total bolt resisting strength is 119 kips $(529.6 \mathrm{kN})$.

\section{Numerical analysis:}

Modeling: To simulate the experiment, a threedimensional solid model, shown in Fig. 7, was developed and solved using the FE analysis program, ANSYS. The nominal specimen dimensions were used to define the model geometry. Figure 8 identifies the different element types used to create the model. SOLID45 8 node solid elements were used for the plates. The bolt shanks were defined by PREST179 to allow the application of pretension. Two contact areas are used in the FEM. The first area is between the surfaces of the top and bottom plates. The second area is between the bolt shank and the inside surface of the bolt holes of the top and bottom plates. CONTA175 and TARGE170 elements were used to define the contact condition between the two plates and between the bolts and plates. The mesh size is 0.1875 inch $(4.76 \mathrm{~mm})$, which was selected via a mesh convergence study. A total of 8,547 elements were used to represent one half of the specimen. The model consists of three different parts, top plate, bottom plate and bolt. Because the focus of the analysis is plate behavior, the stem plate was not explicitly modeled. The properties of the bolt were configured to take into account the rectangular shape of the bolt stud. Because the project focuses on the plastic behavior of the system, the analysis options include contact, plasticity, pretension and large displacements.

Boundary conditions and material properties: A symmetric boundary condition was applied to half of the surface and a fixed boundary condition was applied for the entire bottom plate and bottom of the bolt stud. Bolt pretension was applied with 8 kips $(35.6 \mathrm{kN})$ to simulate a hand-tightened condition of the bolts. The loading was applied on the top plate where the stem plate was connected. The maximum applied load was 36 kips $(160.2 \mathrm{kN})$. The measured material properties were utilized within the model properties. The trilinear material models used for the plate and bolt elements are shown in Fig. 9. 
Am. J. Engg. \& Applied Sci., 4 (4): 477-484, 2011

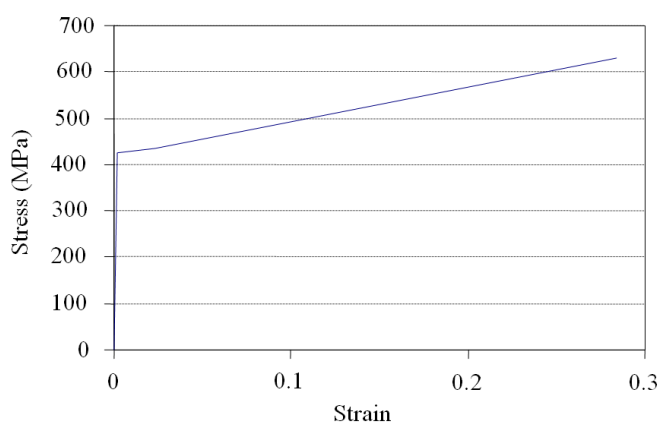

(a)

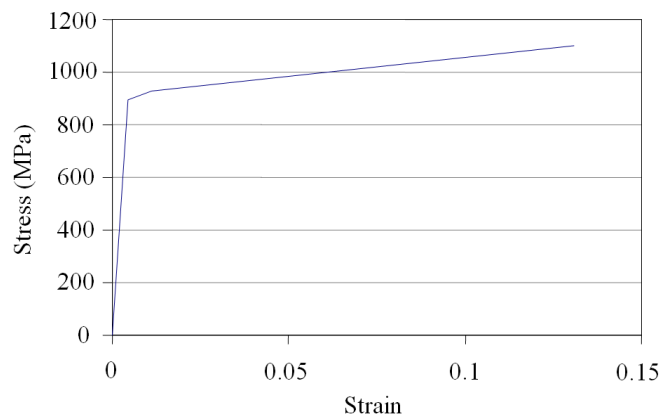

(b)

Fig. 9: Element material properties (a) Plate (Solid 45) stress-stain curve (b) Bolt (Pretel 179) stressstrain curve

\section{RESULTS}

Figure 10a shows the deformed shape and VonMises stress contours at the maximum applied load (36 kips $(160.2 \mathrm{kN}))$. To check the general behavior of the system, the prying effects and contact effects are observed from the stress contour view. The prying force is observed at the bottom plate edge, as indicated by the concentrated stresses at the point of contact. The contact effects between the bolt shank and the bottom plate hole also are observed in Fig. 10b.

The maximum displacement occurred in the top plate at the location of the applied loading line. The load-displacement response of the T-stub specimen is shown in Fig. 11. The top plate started to yield at approximately $17 \mathrm{kips}(75.65 \mathrm{kN})$ and the system exhibited large displacement as the load continued to increase beyond this yield point. The observed response essentially is bilinear, as it exhibits two distinct stiffnesses.

The propagation of stress through the system is illustrated in Fig. 12 as the load increases. The contour is the Von-Mises stress and the deformation is real scale. The development of the plate yield line mechanism is apparent.

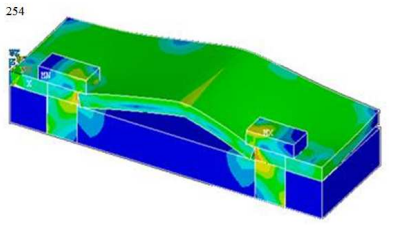

(a)

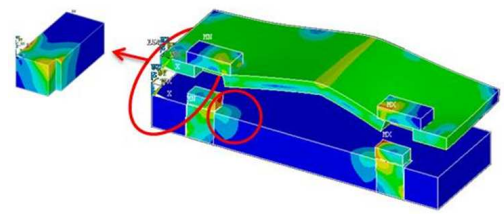

(b)

Fig.10: Behavior of FEM analysis (a) Von-mises stress contour at $160 \mathrm{kN}$ loading (b) Prying effect and contact effect

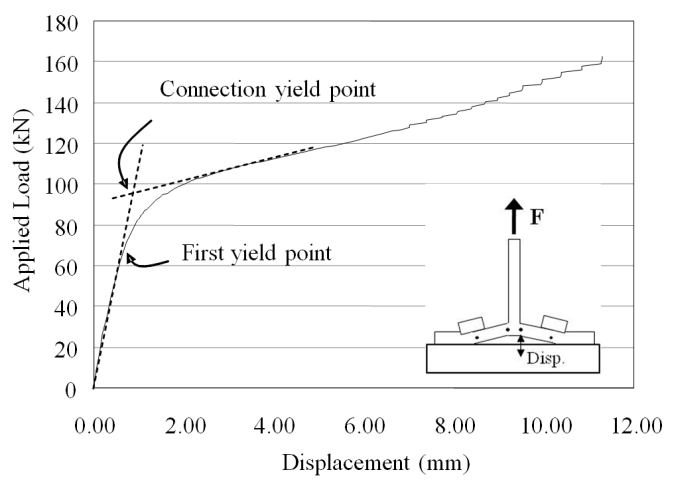

Fig. 11: Load displacement graph (Center of loading line)
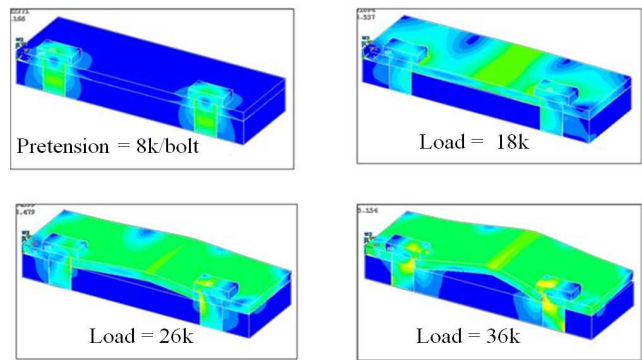

Fig. 12: Von-mises contour and deformation

Experimental investigation:

Specimens: Four full-scale T-stub tests were conducted to verify the analytical procedures presented in this study. As shown in Fig. 13, the same test specimen geometry and test setup were utilized for all tests. However, the bolt strength was varied to isolate the plate and bolt failure modes. 
Am. J. Engg. \& Applied Sci., 4 (4): 477-484, 2011

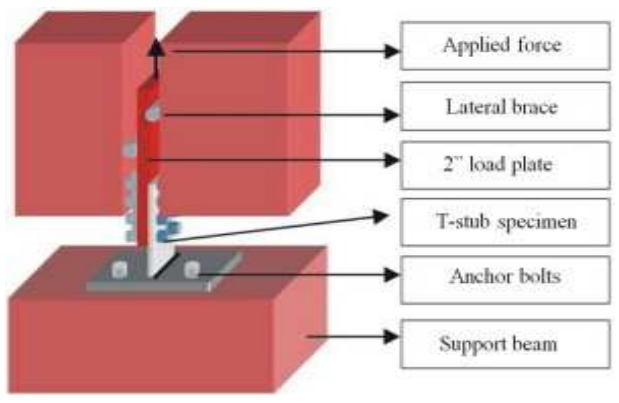

Fig. 13: Test setup
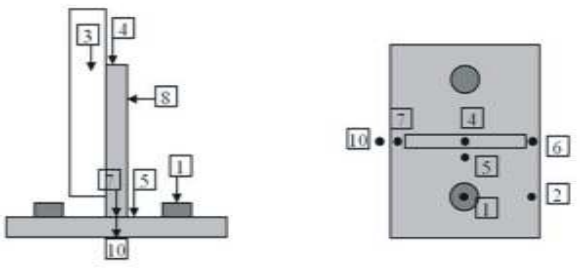

Fig. 14: Instrumentation of specimens

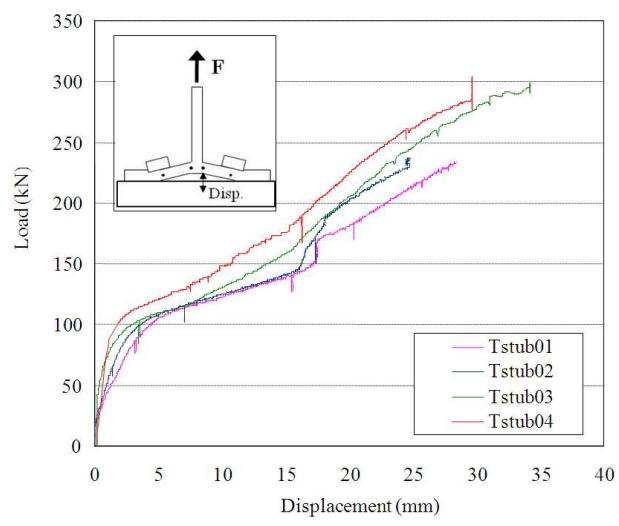

Fig. 15: Center point vertical displacement

Phase One testing used D $7 / 8 \times$ L41/2 A 325 bolts and Phase Two testing used D $7 / 8 \times$ L41/2 A 490 bolts. All of the test bolts were hand-tightened using a wrench and the hand-tightened bolt tension was measured using a Skidmore bolt calibrator to be approximately 8 kips/bolt ( $35.6 \mathrm{kN} / \mathrm{bolt})$. Figure 6 shows the specimen configuration and geometry. Each specimen was fabricated with a base plate and stem plate using A572 Grade 50 steel. The base plate was welded to the stem plate with a 3/4" fillet weld and using Metal Arc or similar welding and E70xx electrodes on only one side.

Test setup: For the experimental tests, a fixture was fabricated to hold the boot and track assembly level so that the stem of the T-stub was vertical.

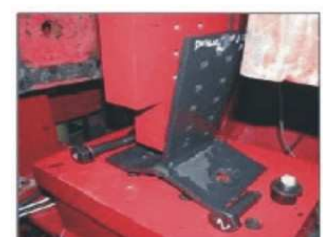

(a)

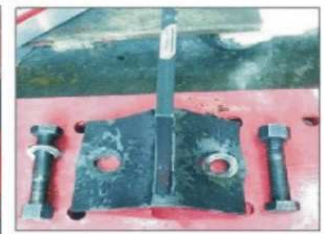

(b)
Fig. 16: Ultimate failure modes (a) Phase 1(b) Phase 2

Table 2: Test results summary

\begin{tabular}{llll}
\hline Phase & Specimen ID & Failure modes & Max. Applied load \\
\hline 1 & Tstub01 & Bolt fracture & $54.39 \mathrm{k}(242 \mathrm{kN})$ \\
& Tstub02 & Bolt fracture & $52.75 \mathrm{k}(235 \mathrm{kN})$ \\
2 & Tstub03 & Base plate tearing & $66.35 \mathrm{k}(295 \mathrm{kN})$ \\
& Tstub04 & Base plate tearing & $63.79 \mathrm{k}(284 \mathrm{kN})$ \\
\hline
\end{tabular}

The stem of the T-stub was attached to a 2-inch (19 $\mathrm{mm})$ thick steel loading plate using $1 / 2$ " $\times 3$ " $(12.7 \times 76.2$ mm) A325 bolts designed to simulate a column in a building. To ensure that the stem and loading plate remained vertical and did not have any out-of-plane movement, the steel plate was laterally braced using rollers. One roller was placed at the bottom of the steel plate in the middle of the bolt pattern that connected it to the boot stem. A $3 / 4$ in $(19 \mathrm{~mm})$ plate with oversized holes in it was used to offset the roller from the plate to ensure that it did not bear on the bolts. Another roller was placed approximately 12" (304.8 $\mathrm{mm}$ ) higher on the plate on the other side. These rollers were supported and braced against the test fixture. A computercontrolled hydraulic cylinder was used to apply the vertical load through the load plate.

Instrumentation: Ten linear potentiometers were used to measure the specimen displacements for this test, as shown in Fig. 14. A computer-controlled Vishay data acquisition system was used to record the load and displacement data points. Six linear potentiometers (1, 2, 5, 6, 7 and 9) were placed on the surface of the Tstub specimen to measure the vertical deflection. Three linear potentiometers (3, 4 and 10) were used to measure the test setup movement for the vertical direction. One linear potentiometer (8) was placed at the stem surface to measure the lateral displacement of the specimen.

Loading procedures: At the beginning of each test a small preload was applied to check the behavior of the test setup and instrumentation. The test load was applied in displacement control mode and a displacement rate of 0.1 in. $\min ^{-1}\left(2.54 \mathrm{~mm} \mathrm{~min}^{-1}\right)$ was used.

Results: The load-deflection responses for the four tests are shown in Fig. 15. Linear potentiometer 5 (as shown in Fig. 14) is used as the reference displacement. 
All of the tests that were performed exhibited similar behavior. However, the Phase Two tests showed slightly stiffer behavior and a higher ultimate load than the Phase One tests. A summary of results is presented in Table 2.

Figure 16 shows the ultimate failure mode of the tests. Due to the large deflection and prying effect, the Phase One ultimate failure mode was bolt tension rupture. However, the ultimate failure mode for Phase Two testing was base plate bolt hole tear-out. This ultimate failure mode change was expected, because these tests used the stronger A490 strength bolts.

\section{DISCUSSION}

Figure 17 shows the yield line pattern sketched on the experimental test photograph and the FEM analysis results. The observed yield line pattern in both cases is similar to the selected yield line pattern.

A comparison of the load displacement responses of the experimental tests (Tstub03 and Tstub04), FEM and yield line is shown in Fig. 18. The forcedisplacement curves obtained from the numerical analysis show rather good agreement with the experimental results. In particular, the yield limit of the theoretically obtained line is very close to both the experimental and numerical yield levels.

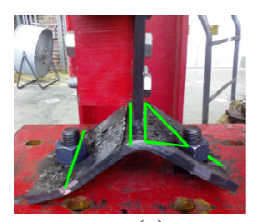

(a)

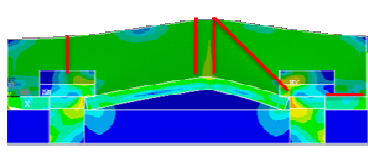

(b)
Fig. 17: Experimental and FEM yield line pattern(a) Tstub04 at end of test (b) Von-mises stress at $160 \mathrm{kN}$

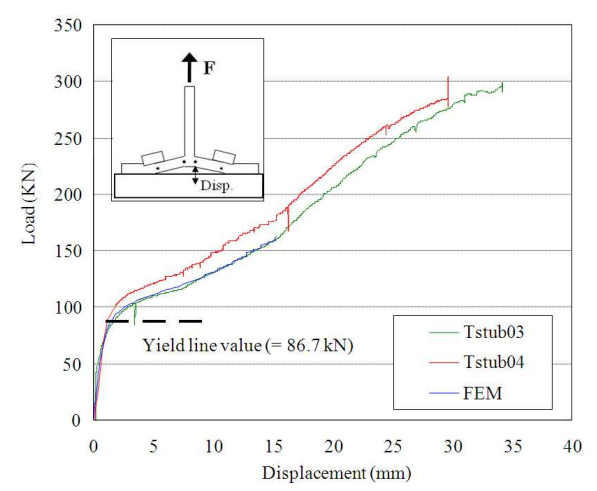

Fig.18: Comparison of test, FEM and yield line results

\section{CONCLUSION}

As an alternative seismic moment resisting frame connection, the EPMC became the subject of focus after the Northridge earthquake of 1994. To simplify the connection analysis, the T-stub was used as a reduced EPMC. The objective of this study is to employ various analysis methods to verify the characteristics of the reduced EPMC. Three different approaches are adopted in this research to analyze the reduced EPMC (T-stub). Yield line analysis defines the yield limit of the system and numerical analysis (FEM) verifies the theoretical results and simulates the behavior of the experimental test. Based on the results of this comparative study, the following conclusions can be drawn:

- Yield line theory can be used to predict the end plate flexural yield force with a correct yield line pattern

- The numerical model (FEM) can accurately simulate the behavior of the end plate

- Yield line theory and numerical modeling can be used together as preanalysis tools to simulate EPMC experimental test behavior

\section{ACKNOWLEDGEMENT}

This research was supported by The Steel Network, Inc. (TSN). The findings and opinions expressed in this study, however, are those of the authors alone and not necessarily the views of the sponsoring agency.

\section{REFERENCES}

AISC, 2002. AISC Design Guide 16: Flush and Extended Multiple-Row Moment End-Plate Connections. American Institute of Steel Construction, Chicago.

Borgsmiller, J.T., 1995. Simplified Method for Design or Moment End-Plate Connections. 1st Edn., Virginia Polytechnic Institute and State University, Blacksburg, VA, pp: 396.

Bursi, O.S., F. Ferrario and V. Fontanari, 2002. Nonlinear analysis of the low-cycle fracture behaviour of isolated Tee stub connections. Comput. Struct., 80: 2333-2360. DOI: $10.1016 /$ S00457949(02)00252-3

FEMA, 2000. Recommended Seismic Design Criteria for New Steel Moment-Frame Buildings. Federal Emergency Management Agency, Washington, DC. 
Garlock, M.M., J.M. Ricles and R. Sause, 2003. Cyclic load tests and analysis of bolted top-and-seat angle connections. J. Struct. Eng., 129: 1615-1625.

Hendrick, D., A.R. Kukreti and T.M. Murray, 1984. Analytical and experimental investigation of stiffened flush end-plate connections with four bolts at the tension flange. University of Oklahoma, Norman.

Jenkins, W.M. and R. Stainsby, 1981. Joints in Structural Steelwork. London-Toronto: John Wiley and Sons, New York, ISBN: 0470271639, pp: 825.

Mazzolani, F.M. and R. Tremblay, 2000. Behaviour of Steel Structures in Seismic Areas. 1st Edn., Taylor and Francis, Canada, ISBN-10: 9058091309, pp: 764.

Meng, R.L., 1996. Design of moment end-plate connections for seismic loading. Ph.D. Dissertation, Virginia Polytechnic Institute and State University, pp: 480.
Morrison, S.J., A. Astaneh-Asl and T.M. Murray, 1986. Analytical and Experimental Investigation of the Multiple Row Extended 1/3 Moment End-Plate Connection with Eight Bolts at the Beam Tension Flange. University of Oklahoma.

Murray, T.M., 1988. Recent developments for the design of moment end-plate connections. J. Construction Steel Res., 10: 133-162. DOI: 10.1016/0143-974X(88)90029-6

Srouji, R., A.R. Kukreti and T.M. Murray, 1983. Yield-line analysis of connections with bolt force predictions. Report No. FSEL/MBMA 83-05,A University of Oklahoma, Norman, Oklahoma.

Sumner, E.A. and T.M. Murray, 2002. Behavior of extended end-plate moment connections subject to cyclic loading. J. Struct. Eng., 128: 501-508. DOI: 10.1061/(ASCE)0733-9445(2002)128:4(501) 